\title{
Innovations in gas permeable multifocal contact lenses
}

\author{
Edward S Bennett \\ College of Optometry, University \\ of Missouri-St. Louis, St. Louis, \\ MO 63।2I, USA
}

This article was published in the following Dove Press journal:

Clinical Optometry

8 September 2010

Number of times this article has been viewed
Correspondence: Edward S Bennett College of Optometry, University of Missouri-St. Louis, One University Boulevard, St. Louis, MO 63121, USA

Tel + I 3145166258

Fax +I 3145166708

Email ebennett@umsl.edu

\begin{abstract}
A current area of great consumer interest, as well as potential for practice growth, pertains to the contact lens correction of presbyopia. In particular many recent innovations with gas permeable multifocal lens designs have resulted in them comparing favorably - and often superiorly - to both soft multifocal lenses and monovision lenses, notably in the area of quality of vision. Gas permeable (GP) back surface aspheric multifocal designs have become increasingly popular because newer designs often are able to incorporate higher add powers than their predecessors, often via the addition of add power to the front surface of the lens. In addition, several front surface lens designs have recently been introduced which have the benefits of minimizing any corneal topography changes as they are typically fit in alignment with the cornea, while also providing a higher add than can be provided on the back surface of the lens. Some high specific gravity materials have been introduced which potentially allow for thinner lenses which have less mass and may exhibit more consistent centration than aspheric multifocal designs in conventional materials. New segmented, translating designs are available with the ability to provide an intermediate correction while the introduction of a hybrid design provides the practitioner with a viable option when a GP lens results in either poor centration of excessive subjective awareness.
\end{abstract}

Keywords: presbyopia, contact lens, add power

\section{Introduction}

It is evident that the greatest potential growth in the contact lens market today is the presbyopic patient. As the presbyopic population worldwide is rapidly growing and represents the largest segment of the population, it is still well underrepresented in the contact lens market. ${ }^{1-4}$ Data from annual contact lens fitting surveys have found that less than $40 \%$ of contact lens wearers older than 45 years of age are prescribed a presbyopic contact lens correction. ${ }^{5}$ Some of this problem may pertain to potential multifocal contact lens patients not being informed of this option. A 2007 survey by the Contact Lens Council reported that $40 \%$ of patients who responded were unaware that their presbyopia could be corrected by multifocal contact lenses. ${ }^{6}$ In addition, $75 \%$ of contact lens wearers and $60 \%$ of spectacle wearers indicated interest in wearing them. Jones et $\mathrm{al}^{7}$ found that if the practitioner is proactive in recommending contact lenses, 21 of 33 presbyopic patients agreed to be fitted with contact lenses.

\section{Gas permeable multifocals: how do they compare to soft lens multifocals and monovision?}

Monovision is defined as correcting one eye for distance vision and the other eye for near vision. For several decades monovision was the most popular contact lens 
correction modality for presbyopia. The success rate for monovision has been reported to be between $70 \%$ and $76 \%, 8,9$ although a recent report indicated a lower success rate of between $59 \%-67 \% .{ }^{10}$ Monovision does have several benefits including only changing one lens for current contact lens wearers, ease of fitting, less lens cost, and uninterrupted vision out of each eye separately. ${ }^{11-13}$ However, there are several compromises associated with monovision correction including stereoacuity loss, notably as the add power increases. ${ }^{14,15}$ Likewise, with add power increase, monocular suppression of blur occurs. ${ }^{16}$ Contrast sensitivity loss and compromise on critical distance vision tasks have also been reported. ${ }^{17,18}$ Interestingly, 29\% of monovision wearers have been found to have an increase in anisometropia in their refractive correction of, at minimum, 0.50D. ${ }^{19}$ In addition, problems with night driving and, in particular, glare from headlights, has also been reported. ${ }^{20-22}$

Several studies comparing soft lens bifocals to monovision have found that, when subjects have worn both modalities and presented with a forced choice situation, anywhere from $68 \%-76 \%$ selected the soft bifocal lens. ${ }^{23-25}$ In addition, a significant reduction in stereopsis has resulted with subjects wearing a monovision correction versus soft lens bifocals. ${ }^{9,24,26}$ The results of a study in which subjects wore GP multifocals for 6 weeks followed by monovision for 6 weeks (or vice versa) resulted in $75 \%$ of the subjects preferring the multifocal correction. ${ }^{27}$ Therefore, it is evident from clinical research that if patients are allowed the opportunity to choose between these two modalities, they are more likely to select a multifocal correction versus monovision. Concurrently, there appears to be a general market trend toward multifocals. In a recent publication that provided the results of a survey of 445 contact lens practitioners it was found that $68 \%$ of practitioners reported that multifocal contact lenses were their preferred modality for presbyopic correction, whereas only $22 \%$ preferred monovision and $8 \%$ preferred single vision contact lenses with reading spectacles. $^{28}$ These results can be compared to a similar survey performed one year prior in which $59 \%$ of the respondents preferred multifocal contact lenses, $27 \%$ preferred monovision, and $14 \%$ preferred single vision contact lenses and reading spectacles. ${ }^{29}$

Comparison studies between soft bifocal and multifocal designs versus GP bifocal and multifocal lenses have resulted in better visual performance from the GP modality. Ueda and Inagaki ${ }^{30}$ compared short-term visual performance in subjects who wore both soft and GP bifocal designs. They concluded that bifocal GP lenses resulted in better visual performance - notably at near - than soft bifocal lenses. A more comprehensive study evaluated the visual performance of subjects wearing progressive addition spectacle lenses (PALs), GP monovision, soft bifocal and GP multifocal contact lenses. ${ }^{31}$ The results showed relative parity between the binocular high and low contrast acuity between GP multifocal wearers and PAL wearers followed by soft bifocal wearers and then monovision (Figure 1). Between the three contact lens groups, GP multifocal lens wearers exhibited the highest binocular contrast sensitivity at all spatial frequencies.

\section{Innovations in GP lens designs}

The trend away from monovision as the preferred modality as well as the superior visual performance of GP versus soft presbyopic lens designs, should continue as a result of several recent lens design and material innovations. These include posterior surface aspheric multifocal designs with additional add power on the front surface, front surface aspheric multifocal designs, high specific gravity lens materials, segmented translating designs innovations including intermediate correction and thinner profiles, and hybrid multifocal designs.

\section{High add back surface aspheric multifocal designs}

Although there is some shifting up or translation of an aspheric multifocal design when the patient views inferiorly to read, all aspheric GP multifocals (and all soft lens presbyopic designs in common use) utilize the principle of simultaneous vision in which near and distance corrections are in front of the pupil at the same time. In addition, another traditional limitation of this design is the inability to achieve a high add on the back surface. As these are pupil dependent designs, typically with the optimum distance correction in the center followed by a gradual increase in plus power toward the periphery, individuals with a large pupil diameter (ie, $\geq 6 \mathrm{~mm}$ in room illumination) are not good candidates due to the increased compromise with distance vision, notably in low illumination conditions (ie, night driving). ${ }^{11}$ Therefore, the add power on the back surface is typically optimum for early presbyopes; however, to achieve the add required in moderate-to-advanced presbyopia, several recently introduced designs are available with additional add power on the front surface. One such representative design is the Essential $\mathrm{CSA}^{\circledR}$ design (Blanchard Contact Lens Inc, Manchester, NH, USA). The back surface is an aspheric multifocal design and the front surface has a concentric distance 


\section{High and low contrast acuity}

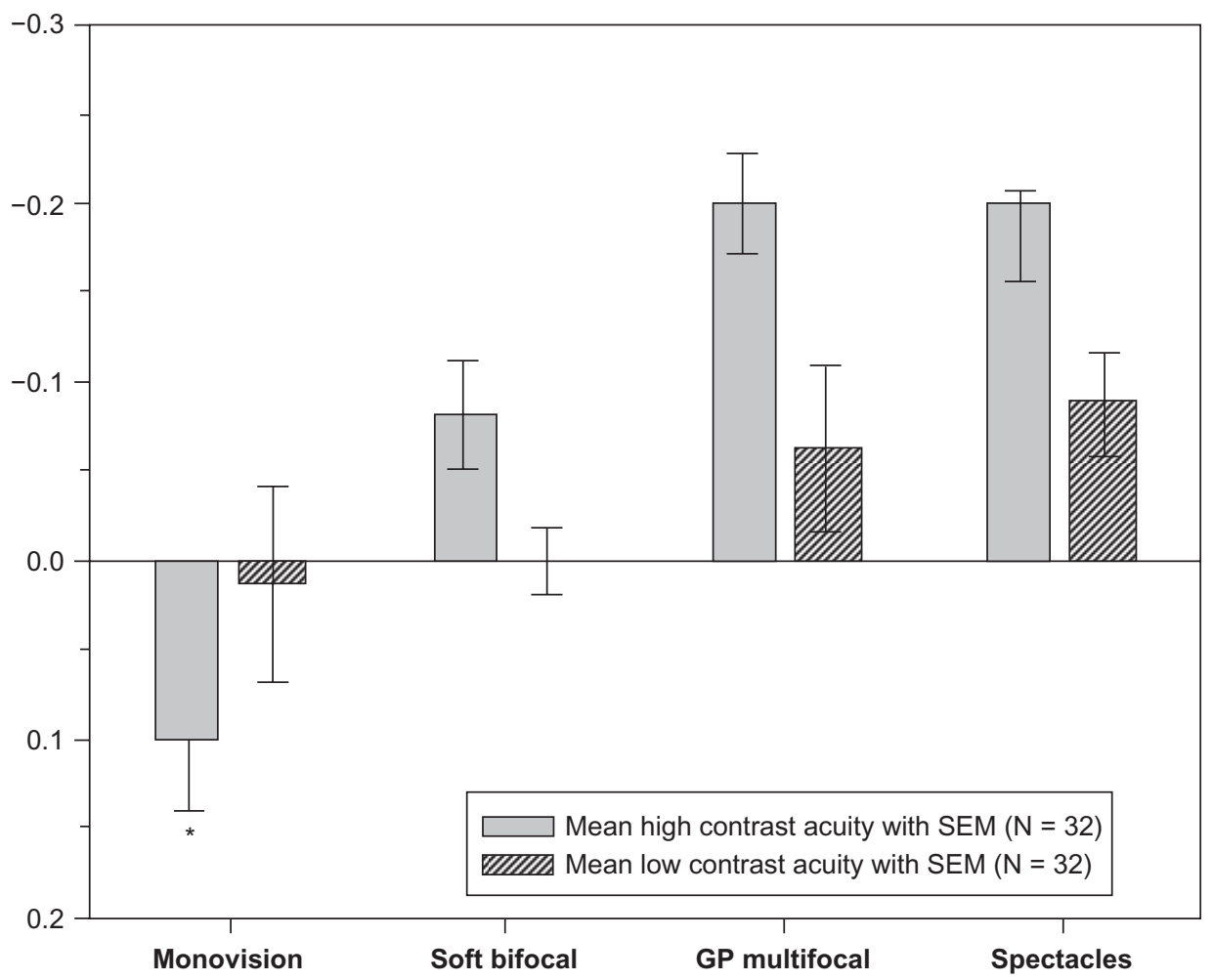

Figure I Vertical light grey bars represent mean high contrast acuity in log MAR units and vertical dark grey bars with oblique lines represent mean low contrast acuity for subjects wearingmonovision, soft bifocal, GP multifocals and spectacles. Error bars represent standard error of the means. The asterisk indicates a significant difference from the other groups. Reproduced with permission from Rajagopalan AS, Bennett ES, Lakshminarayanan V. Visual performance of subjects wearing presbyopic contact lenses. Optom Vis Sci. 2006;83(8): 6II-615. ${ }^{31}$ (C) The American Academy of Optometry 2006.

power zone (4.0-4.6 $\mathrm{mm})$ surrounded by a concentric zone that provides the additional add power required by someone with moderate-to-high presbyopia. When the patient views inferiorly, and the lens shifts superiorly, they should be viewing through the region of the lens with additional add power.

\section{Front surface multifocal designs}

The challenges provided by back surface aspheric multifocal designs include the limited add power, not only on the back surface but also if the lens does not translate with downward gaze. Also the base curve selected is typically, at minimum, one diopter steeper than " $\mathrm{K}$ ". This can potentially result in lens adherence and distortion, especially if the lens decenters on the cornea. ${ }^{11}$ The benefits of front surface aspheric designs include that they can be fit with corneal alignment (ie, approximating an "On $\mathrm{K}$ " base curve radius selection) minimizing the risk of corneal distortion; in addition, it has been found that a higher add can be placed on the front surface than on the back surface. ${ }^{32}$ Many of these designs also have aberration-control optics on the front surface to optimize the quality of vision.
Numerous front surface aspheric multifocal lenses have recently been introduced. The Naturalens Progressive ${ }^{\circledR}$ front surface aspheric design (Advanced Vision Technologies Ltd, Golden, CO, USA) has unlimited add powers via varying the central distance zone from $2.5-5.5 \mathrm{~mm}$ and is available in a comprehensive Dispensing Inventory System (Figure 2). One of the benefits of all aspheric multifocal designs is the ease of fitting. In fact, empirical fitting of these designs has been recommended with success often achieved with the first pair of lenses dispensed to the patient. ${ }^{33,34}$ This is an important benefit as the first pair of lenses fit to the patient often results in good vision at all distances. The Reclaim ${ }^{\circledR} \mathrm{HD}$ Bi-Aspheric Multifocal lens design (Blanchard Contact Lens) has mild asphericity on the back surface, with most of the add power on the front surface. One benefit of this design is simply that the company does not provide diagnostic fitting sets as an incentive to order these lenses for a given patient. In addition, for the increasing number of post-refractive surgery patients who have entered presbyopia, this laboratory has recently introduced a design with their RSS (Refractive Surgery Specific) reverse geometry back surface in combination with the Reclaim ${ }^{\circledR}$ multifocal front surface. (Figure 3) 


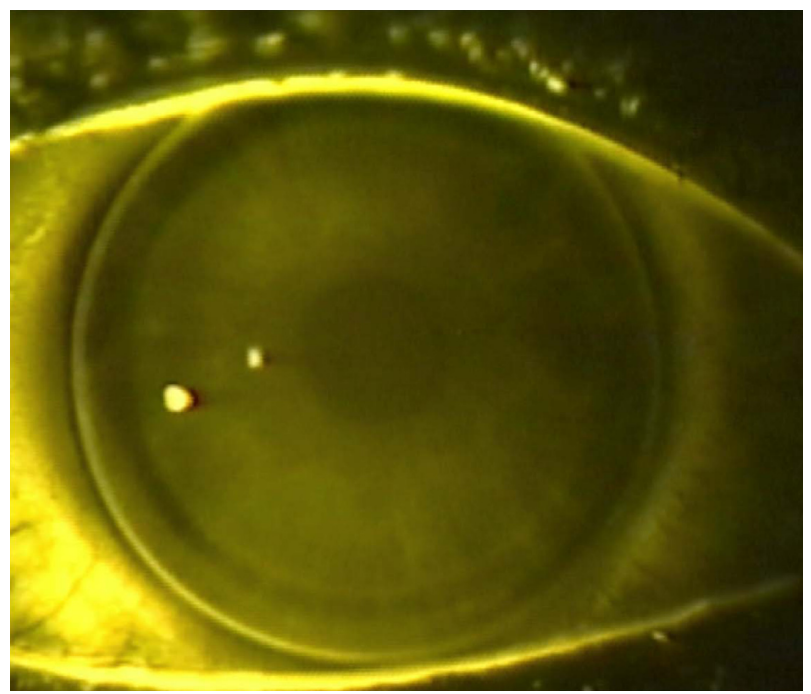

Figure 2 The Naturalens Progressive multifocal lens (courtesy of Advanced Vision Technologies)

\section{High index of refraction (IOR) lens materials}

Recently, several lens materials with high index of refraction and low specific gravity have been introduced. These lens materials currently include the Optimum $\mathrm{HR}^{\circledR}$ materials (Contamac Ltd, Saffron Walden, UK) with a specific gravity of 1.04 and IOR of 1.51 (Hirafocon A) and 1.53 (Hirafocon B) and the Paragon HDS $\mathrm{HI}^{\circledR}$ (Paragon Vision Sciences, Phoenix, AZ, USA) with a specific gravity of 1.12 and IOR of 1.54. Other GP lens materials have specific gravity values between $1.10-1.27$ and IOR values between $1.42-1.47$. The benefits of these materials includes thinner center-to-edge profiles resulting in less mass and potential improvement

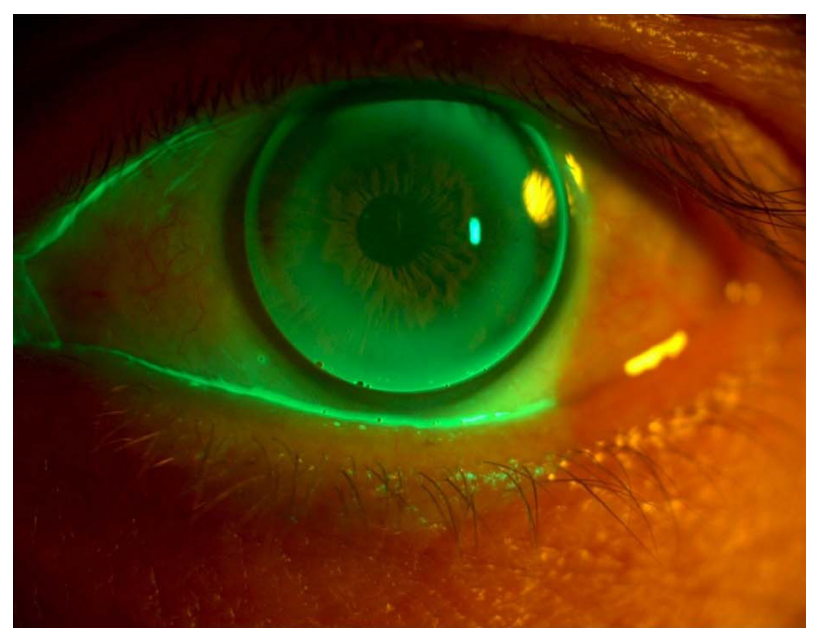

Figure 3 The RSS (Refractive Surgery Specific) reverse geometry back surface in combination with the Reclaim ${ }^{\mathrm{TM}}$ multifocal front surface (courtesy of Blanchard Contact Lens). in centration and initial comfort. ${ }^{35}$ In addition, an increased add power versus other materials has been found. In fact, at $2.5 \mathrm{~mm}$ away from the lens center, a front surface aspheric design in a high IOR material results in an add power of $2.36 \mathrm{D}$ compared to a back surface aspheric design in a high IOR material (2.12D add) and a back surface aspheric design in a conventional material (1.75D add). ${ }^{32}$

\section{Translating segmented design innovations}

\section{Translating designs with intermediate correction}

Traditional bifocal segmented translating designs in which the upper portion of the lens had distance correction and the lower section has near correction has resulted in the highest success rates of any contact lens presbyopic correction due to the quality of vision achieved at both distances. ${ }^{36,37}$ However, these designs have required the incorporation of prism ballast to allow the lens to position at or near the lower lid, such that the lens can be pushed superiorly with downward gaze. In addition, with the fact that most presbyopic individuals manifesting a moderateto-advanced add requirement have intermediate vision needs, several manufacturers have introduced segmented, translating designs incorporating an intermediate correction. This includes executive intermediate designs Llevations $^{\circledR}$ (from Tru-Form Optics, Euless, TX, USA); Tangent Streak Trifocal ${ }^{\circledR}$ (from Firestone Optics, Kansas City, MO, USA); aspheric intermediate optics, Presbylite (from Lens Dynamics, Denver, CO, USA); EZEyes Multifocal ${ }^{\circledR}$ (from Abba Optical Inc, Stone Mountain, GA, USA) and a segmented, translating bifocal front surface in combination with an aspheric back surface multifocal (ESSential Solutions ${ }^{\circledR}$ from X-Cel, Duluth, GA, USA).

\section{Thinner profile translating designs}

A recently introduced design, Bi-Expert ${ }^{\circledR}$ (Art Optical Inc, Grand Rapids, MI, USA), has the base of the prism designed as an inverse curve resulting in equal edge thickness $360^{\circ}$ around the edge circumference. ${ }^{38}$ The slab-off technology used in this design results in less overall mass and greater potential initial comfort (Figure 4). This design also has the advantage of being ordered empirically. The laboratory can be provided with keratometry readings, refraction and (preferably) anatomical information to include pupil diameter, horizontal visible iris diameter, lower lid to lower pupil distance, palpebral fissure width, and lid tonicity. The primary limitation of this design is the absence of an intermediate correction although in a recent study, only two subjects failed due to this problem. ${ }^{39}$ 


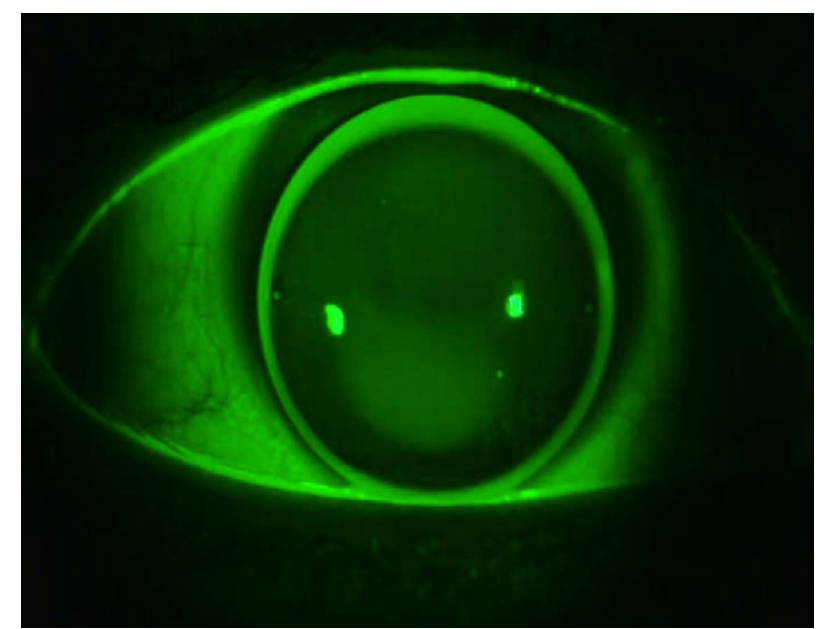

Figure 4 The Bi-Expert bifocal lens (courtesy of Art Optical).

\section{Hybrid multifocal designs}

When decentration or initial lens awareness are problematic with presbyopic individuals desiring good vision at multiple distances, the recent introduction of a hybrid multifocal lens design would be a viable option. ${ }^{40}$ The SynergEyes ${ }^{\circledR}$ (SynergEyes, Inc, Carlsbad, CA, USA) lens has a 100-Dk GP center and a 27-percent water content skirt in a center-near design. This lens is available in two near zone diameters, $1.9 \mathrm{~mm}$ and $2.2 \mathrm{~mm}$, allowing the fitter to vary the size of this zone between eyes if better distance vision is necessitated.

\section{Summary}

It is apparent that the introduction of high refractive index lens materials, in combination with front surface aspheric multifocal designs and advanced manufacturing techniques resulting in high optical quality and aberration control, bodes very well for contact lens correction of presbyopia. In addition, the introduction of modern segmented translating multifocal and hybrid designs provides numerous tools for the increasing number of presbyopic patients interested in contact lens wear.

\section{Disclosure}

The author declares no conflict of interest.

\section{References}

1. Schwartz CA. Portrait of a presbyope in 1999. Optom Today; 1999(Suppl):5-7.

2. Meyler J, Veys J. A new pupil-intelligent design for presbyopic correction. Optician. 1999;217:18-23.

3. Edwards K. Contact lens problem-solving: bifocal contact lenses. Optician. 1999;218:26-32.

4. Bennett ES, Jurkus JM. Presbyopic correction. In Bennett ES, Weissman BA, eds. Clinical Contact Lens Practice, 2nd ed. Philadelphia: Lippincott Williams and Wilkins; 2005:531-548.

5. Morgan PB, Efron N. Contact lens correction of presbyopia. Contact Lens and Anterior Eye. 2009;32:191-192.
6. Contact lens council. New survey finds more education on contact lenses and lens care will help consumers see 20/20 PR newswire 2007 August 15.

7. Jones L, Jones D, Langley C, et al. Reactive or proactive contact lens fitting - does it make a difference? J Br Contact Lens Assoc. 1996;19: $41-43$.

8. Westin E, Wick B, Harrist RB. Factors influencing success of monovision contact lens fitting: survey of contact lens diplomates. Optometry. 2000;71:757-763.

9. Jain S, Irora I, Azar DT. Success of monovision: review of the literature and potential applications to refractive surgery. Surv Ophthalmol. 1996; 40:491-499.

10. Evans BJ. Monovision: a review. Ophthal Physiol Opt. 2007;27: 417-439.

11. Bennett ES, Henry VA. Bifocal contact lenses. In Bennett ES, Henry VA: Clinical Manual of Contact Lenses (3rd ed.). Philadelphia, Wolters Kluwer/Lippincott Williams and Wilkins, 2009:371-409.

12. Bennett ES. Contact lens correction of presbyopia. Clin Exp Optom. 2008;91:265-278.

13. Gasson A, Morris J. Lenses for presbyopia. In Gasset A, Morris J, eds. The Clinical Manual, 3rd ed. London, Butterworth-Heinemann, 2003:298-317.

14. Heath DA, Hines C, Schwartz F. Suppression behavior analyzed as a function of monovision addition power. Am J Optom Physiol Opt. 1986; 63:198-201.

15. Larsen WL, Lachance A. Stereoscopic acuity with induced refractive errors. Am J Optom Physiol Opt. 1983;60:509-513.

16. Collins MJ, Goode A, Brown B. Distance visual acuity and monovision. Optom Vis Sci. 1993;70:723-728.

17. Loshin DS, Loshin MS, Comer G. Binocular summation with monovision contact lens correction for presbyopia. Int Contact lens Clin. 1982;9:161-165.

18. Collins MJ, Brown B, Bowman KJ. Contrast sensitivity with contact lens correction for presbyopia. Ophthalmic Physiol Opt. 1989;9: 133-138.

19. Wick B, Westin E. Change in refractive anisometropia in presbyopic adults wearing monovision contact lens correction. Optom Vis Sci. 1999;76:33-39.

20. Wood JM. Aging, driving and vision. Clin Exp Optom. 2002;85: 214-220.

21. Josephson JE, Caffery BE. Monovision versus aspheric contact lenses: a crossover study. J Am Optom Assoc. 1987;58:652-654.

22. Johannsdottir KR, Stelmach LB. Monovision: a review of the scientific literature. Optom Vis Sci. 2001;78:646-651.

23. Situ P, du Toit R, Fonn D, et al. Successful monovision contact lens wearers refitted into bifocal contact lenses. Eye Contact Lens. 2003; 29:181-184.

24. Richdale K, Mitchell GL, Zadnik K. Comparison of multifocal and monovision soft contact lens corrections in patients with low-astigmatic presbyopia. Optom Vis Sci. 2006;83:266-273.

25. Benjamin WJ. Comparing multifocals and monovision. Contact Lens Spectrum. 2007;22:35-39.

26. Kirschen DG, Hung CC, Nagano TR. Comparison of suppression, stereoacuity and interocular differences in visual acuity in monovision, and Acuvue Bifocal contact lenses. Optom Vis Sci. 1999;76: 832-837.

27. Johnson J, Bennett ES, Henry VA, et al. Multivision ${ }^{\mathrm{TM}}$ vs monovision: a comparative study. Presented at the Annual Meeting of the Contact lens Association of Ophthalmologists, Las Vegas, NV, February, 2000.

28. Nichols JJ. Contact lenses 2009. Contact Lens Spectrum. 2010;25:20.

29. Nichols JJ. Contact lenses 2008. Contact Lens Spectrum. 2009;24: 24-32.

30. Ueda K, Inagaki K. Contrast visual acuity with bifocal contact lenses. Eye and Contact Lens. 2007;33:98-102.

31. Rajagopalan AS, Bennett ES, Lakshminarayanan V. Visual performance of subjects wearing presbyopic contact lenses. Optom Vis Sci. 2006; 83:611-615. 
32. Norman C, Caroline P, Koch T, Svochak J. Do we need high index materials? Presented at the 47th Annual Meeting of the Contact Lens Manufacturers Association. Hoover, Alabama, November, 2008.

33. Ames K. Fitting the presbyope with gas permeable contact lenses. Contact Lens Spectrum. 2001;16:42-45.

34. Benoit KD. Empirical fitting of gas permeable multifocal lenses. Contact Lens Spectrum. 2009;24:41-43.

35. Bennett ES. How high index GP materials will impact your practice. Contact Lens Spectrum. 2009;24:23.

36. Kirman ST, Kirman GS. The Tangent Streak bifocal contact lens. Contact Lens Forum. 1988;13:38-40.
37. Remba MJ. The Tangent Streak rigid gas permeable bifocal contact lens. J Am Optom Assoc. 1988;59:212-216.

38. Norman CW. GP designs for mature presbyopes. Contact Lens Spectrum. 2009;24:17.

39. Morgan B, Lotoczky J, Al-Delaigan B. Clinical evaluation of the Biexpert $^{\mathrm{TM}}$ multifocal lens. Presented at the Global Specialty Lens Symposium, Las Vegas, Nevada, January, 2010.

40. Sorbara LG. Global Specialty Lens Symposium report. Contact Lens Spectrum. 2009;24:30-37.
Clinical Optometry

\section{Publish your work in this journal}

Clinical Optometry is an international, peer-reviewed, open access journal publishing original research, basic science, clinical and epidemiological studies, reviews and evaluations on clinical optometry. All aspects of patient care are addressed within the journal as well as the practice of optometry including economic and business analyses. Basic and clinical

\section{Dovepress}

research papers are published that cover all aspects of optics, refraction and its application to the theory and practice of optometry. The manuscript management system is completely online and includes a very quick and fair peer-review system, which is all easy to use. Visit http://www.dovepress. com/testimonials.php to read real quotes from published authors. 